\title{
DOUBLE CRACKING IN BRITTLE CYLINDRICAL SPECIMENS SUBJECTED TO QUENCHING
}

\author{
Weijing He, Haiyan Li, Siu-Lun Fok*, J. Derek Jackson, Jan R. Wright \\ Nuclear Graphite Research Group \\ School of Mechanical, Aerospace and Civil Engineering, The University of \\ Manchester \\ Manchester M13 9PL, U.K.
}

Tel: 44-(0)-161-2754327, Fax: 44-(0)-161-2754328, alex.fok@manchester.ac.uk

\begin{abstract}
Hollow cylindrical specimens made of the ceramic material, Pyrophyllite, were subjected to quench tests in water. The specimens fractured in a consistent manner with two diametrically opposite longitudinal cracks. Finite element analysis indicates that the primary crack occurred at the stage when the strain energy of the cylinder reached its maximum during the thermal transient process, while the secondary crack was caused by stress waves generated following the primary crack. Experimental observation of the time of fracture and examination of the crack morphology support the numerical predictions. The work reported here may help to shed light on the fracture criterion for brittle cylindrical components under transient thermal and dynamic loadings.
\end{abstract}

\section{Keywords}

Dynamic stress waves, double cracking, brittle materials, cylindrical specimens, quenching, finite element analysis, stress amplification

\section{Introduction}

Components in nuclear reactors can be subjected to both thermal and mechanical loading, which might cause them to fracture in an unstable manner if the material is inherently brittle or becomes so through irradiation embrittlement. Furthermore, stress waves created by the initial or primary cracking might cause further fractures in such components.

Miklowitz was among the first workers to point out that multiple cracking in brittle materials was the result of dynamic stress waves generated by the primary fracture (Ref. 1). The geometry he investigated was a rod under tension. This was followed by the work of Shindler and Kolsky who also demonstrated multiple cracking in brittle rods under four-point bending (Ref. 2).

More recently, Sato and Hashimoto carried out fracture tests on brittle hollow cylinders subjected to static internal pressure (Refs. 3 and 4). When pressure was applied by a gas to the specimens, which were made from the brittle materials, graphite, plaster and cast iron, they all fractured into four pieces with four roughly equally spaced longitudinal cracks. When, however, the pressure was applied by means of a liquid, only a single crack was produced. These workers also considered the effect of a pre-existing notch on the fracture pattern of these cylinders. They found that the number of cracks reduced from four to three, and then to two as notch depth was increased, with the primary crack being always initiated from the notch. 
Kuroda et al have analyzed the above fracture tests on brittle cylinders using the finite element (F.E.) method (Ref. 5). They concluded that the fracture pattern could be the result of secondary and tertiary cracking created by stress waves generated by the primary crack. 
The question arises as to whether multiple cracking resulting from dynamic stress waves could be produced by thermal, rather than mechanical, loading. In an attempt to answer this question, quench tests have been carried out to induce cracking in brittle hollow cylinders. Dynamic F.E. analysis has also been performed to help explain the experimental observations. The results could be of value in assessing the behaviour of cylindrical reactor components subjected to high thermal loading.

\section{Experiments}

\subsection{Method}

The machinable ceramic material, Pyrophyllite, was used in this study. Its properties are given in Table 1. Cylindrical specimens made from this material were heated to temperatures up to $800^{\circ} \mathrm{C}$ in a furnace and then quenched in a cold water bath to suddenly impose an outer surface temperature of $100^{\circ} \mathrm{C}$. As shown in Fig. 1 , the bore of each specimen was sealed by two end caps to prevent water from reaching the inner surface, thus ensuring that the cooling occurred on the outer surface only. The caps were tied together using a nut and bolt arrangement with a slightly loose fit to avoid undue compressive stresses in the cylinder.

Table 1. Properties of Pyrophyllite

\begin{tabular}{|c|c|c|c|c|c|}
\hline $\begin{array}{l}\text { Young's } \\
\text { Modulus } \\
\text { E } \\
(\mathbf{G P a})\end{array}$ & $\begin{array}{c}\text { Thermal } \\
\text { Conductivity } \\
\lambda \\
(\mathbf{W} / \mathbf{m} \cdot \mathbf{K})\end{array}$ & $\begin{array}{c}\text { Coefficient of } \\
\text { Thermal } \\
\text { Expansion } \\
\alpha \\
(\mu \mathrm{m} / \mathrm{m} \cdot \mathrm{K})\end{array}$ & $\begin{array}{c}\text { Poison's } \\
\text { Ratio } \\
v\end{array}$ & $\begin{array}{c}\text { Fracture Toughness } \\
\text { K }_{\text {IC }} \\
\left(\mathbf{M P a}^{1 / 2}\right)\end{array}$ & $\begin{array}{c}\text { Density } \\
\rho \\
(\mathbf{k g} / \mathrm{m} 3)\end{array}$ \\
\hline 25 & 1.5 & 5.0 & 0.25 & 1.4 & 2550 \\
\hline
\end{tabular}

A variety of specimens with different dimensions and geometries were used in the quench tests. Axial V-grooves were machined onto the surface of some of the specimens to investigate the effect of localized stress concentration; see, for example, Fig. 2. The approximate depth of each groove was $1 \mathrm{~mm}$. Details of the specimens tested are summarized in Table 2.

Table 2. Details of quench test specimens

\begin{tabular}{|c|c|c|c|c|}
\hline ID $(\mathbf{m m})$ & OD $(\mathbf{m m})$ & Length $(\mathbf{m m})$ & $\begin{array}{c}\text { Number of } \\
\text { grooves }\end{array}$ & $\begin{array}{c}\text { Number of } \\
\text { specimens }\end{array}$ \\
\hline 20 & 36 & 10 & 1 & 1 \\
\hline 20 & 36 & 20 & 1 & 1 \\
\hline 20 & 36 & 20 & 8 & 11 \\
\hline 20 & 36 & 40 & 8 & 3 \\
\hline 60 & 80 & 50 & 1 & 2 \\
\hline 60 & 80 & 50 & 8 & 5 \\
\hline
\end{tabular}




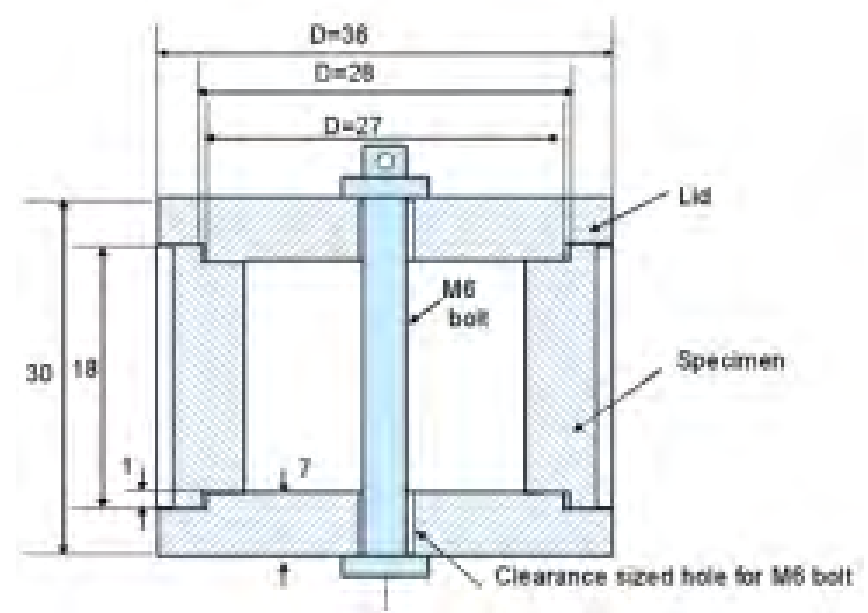

Fig. 1. Sealing arrangement for quench test specimen (dimensions in mm)

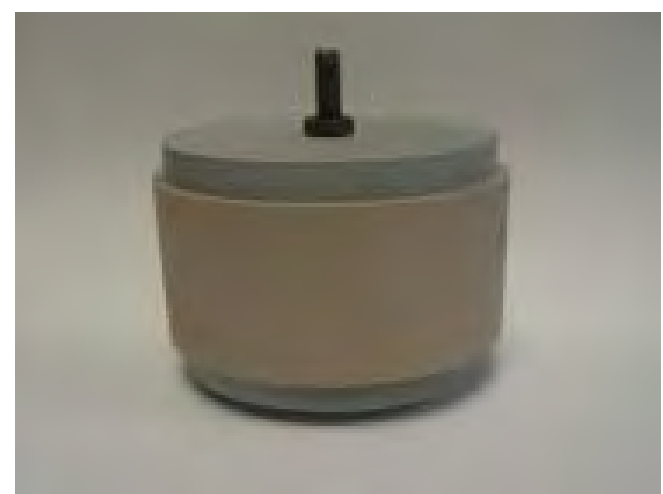

a). Cylindrical specimen without axial grooves $(I D=60 \mathrm{~mm}, O D=80 \mathrm{~mm})$

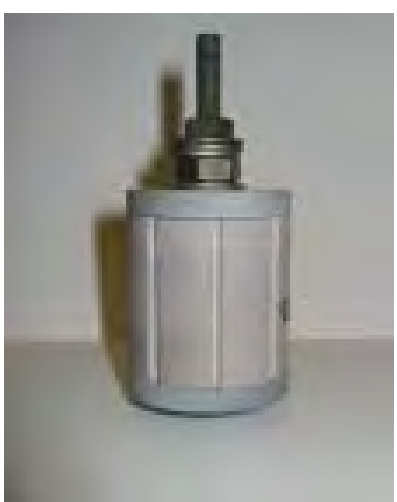

b). Cylindrical specimen with axial grooves at $45^{\circ}$ intervals $(I D=20 \mathrm{~mm}, O D=30 \mathrm{~mm})$

Fig. 2. Assembled quench test specimens of different geometries and dimensions

\subsection{Results}

Fracture of the cylinders occurred a few seconds after they were immersed in the water bath. However, it was necessary to preheat the specimens to a high temperature $\left(800^{\circ} \mathrm{C}\right)$ to cause fracture to take place. Some of the specimens which had been heated to a lower temperature survived the quenching without visible fracture.

When the specimens fractured, almost all of them did so with two apparently simultaneous longitudinal cracks which were diametrically opposite (see Figs. 3 and 4). The only exception was the specimen shown in Fig. 5 which had the two cracks approximately $90^{\circ}$ from each other. No further cracks were evident on the cylinders. Where there were grooves present in a specimen, at least one of the cracks would run along the tip of a groove. 


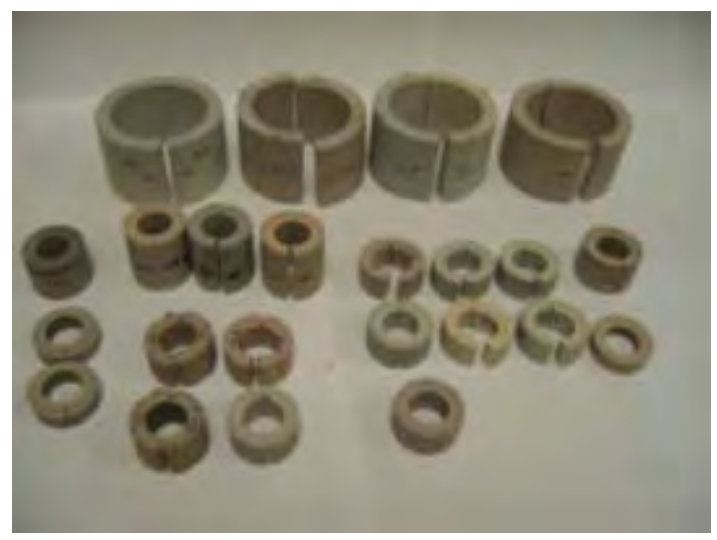

Fig. 3. Pyrophyllite specimens fractured by quenching

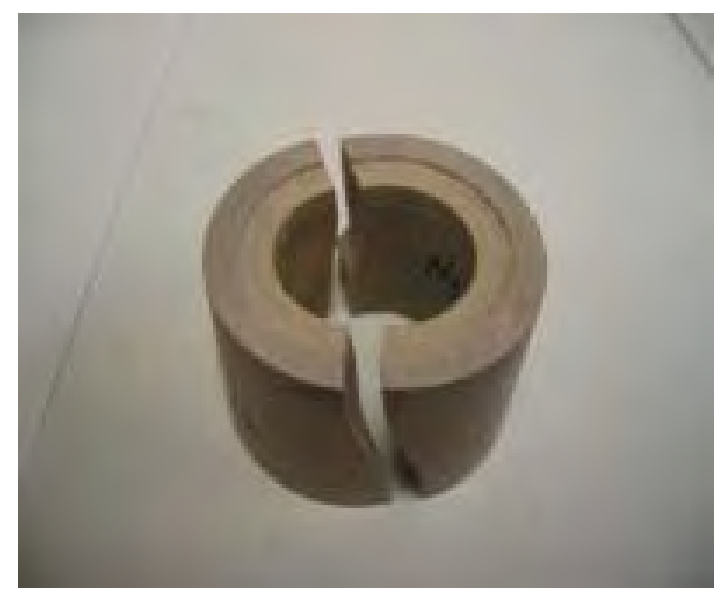

a). Double cracking of cylindrical specimen without grooves

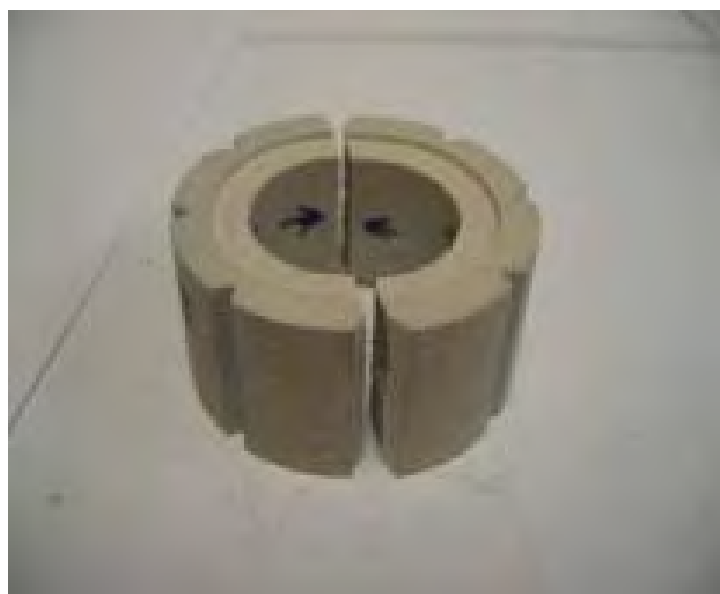

b). Double cracking of cylindrical specimen with grooves

Fig. 4. Pyrophyllite specimens fractured with two diametrically opposite cracks

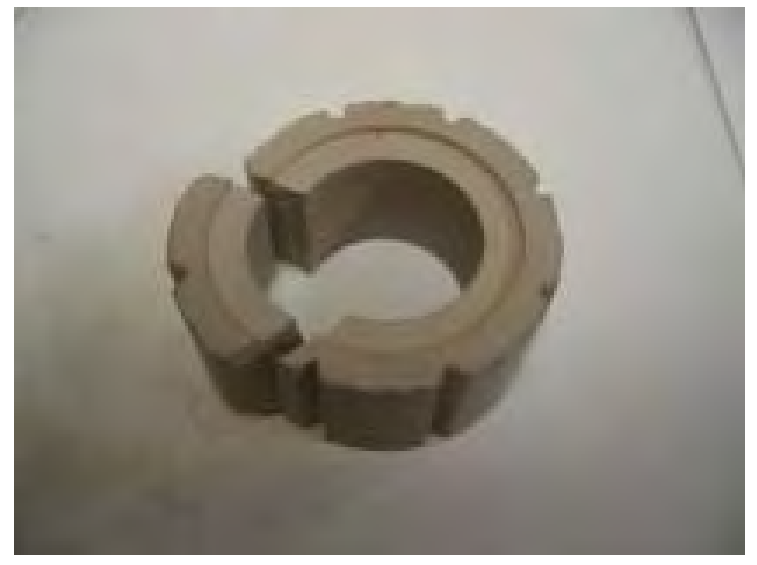

Fig. 5. Pyrophyllite specimen with $90^{\circ}$ double cracking 


\section{F.E. analysis}

ABAQUS (Ref. 6) was used to perform the F.E. analysis. Two-dimensional F.E. models were created for both grooved and ungrooved specimens. Figure 6a shows the model for a hollow cylinder without grooves whose inner diameter was $20 \mathrm{~mm}$ and outer diameter $30 \mathrm{~mm}$. Figure $6 \mathrm{~b}$ shows the model having the same diameters but with eight equally spaced $\mathrm{V}$-grooves, each of $1 \mathrm{~mm}$ depth.

The same mesh was used for both the thermal and dynamic analyses. Eight-node, bi-quadratic, diffusive heat transfer elements were used for the transient thermal analysis (quenching) while eight-node, bi-quadratic, generalized plane-strain elements with reduced integration were used for the dynamic analysis following primary cracking.

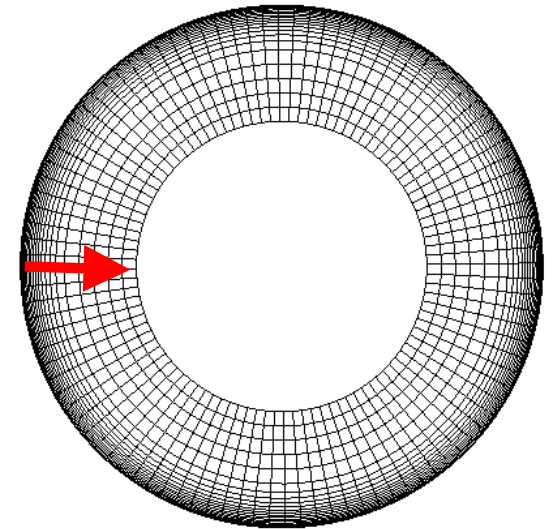

a). FE model of hollow cylindrical specimen without grooves

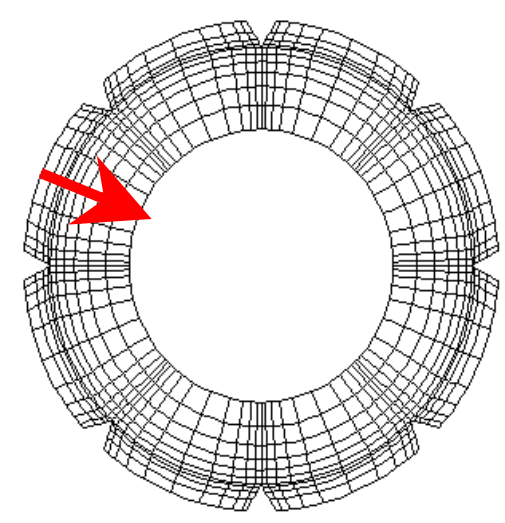

b). FE model of hollow cylindrical specimen with grooves

Fig. 6. FE models used in FE dynamic analysis (arrows indicate paths along which results are sampled)

Possible coupling between the thermal and dynamic behaviors of the system and the interaction between the cylinder and the surrounding water were not considered. The justification for this simplification will be given later. Thus, the transient temperature fields and the resulting thermal stresses in the transient were established first. The latter were then used as initial conditions for the subsequent dynamic analysis following primary cracking.

Dual coincident nodes were provided along a through-thickness radial line to allow modeling of the primary crack. These were tied together, using appropriate boundary conditions, during the thermal transient analysis and the initial stressing of the cylinder prior to primary cracking. For the grooved specimen, the primary crack was assumed to initiate from one of the groove tips. To simulate primary cracking, the boundary conditions holding together the dual coincident nodes were released instantaneously and the sudden release of strain energy generated stress waves that travelled round the 'C-ring' formed after the primary cracking. The interaction of these stress waves with the initial quasi-static thermal stresses was an important factor when considering whether secondary cracking could occur.

\subsection{Transient thermal analysis}

For the transient thermal analysis, the initial temperature of the specimen was set to be uniform at $800^{\circ} \mathrm{C}$. The outside temperature was then decreased to $100^{\circ} \mathrm{C}$ instantaneously to simulate quenching in a water bath. The inner surface was assumed to be fully insulated throughout the process.

Figure 7 shows the transient temperature and hoop stress distributions across the thickness of the ungrooved cylinder. The nodal path along which results were sampled is indicated in Fig. 6 . The modification in the overall temperature and the thermal gradient across the thickness with time can be clearly seen. It took about 50s for the temperature of the whole specimen to reduce to a uniform value equal to that of the outer surface. Very high hoop stresses were generated on the outer skin of the cylinder in the early stages of the thermal transient due to 
the very high thermal gradient there. As time progressed, a more linear stress distribution across the thickness began to develop, which gradually disappeared as the temperature profile became more uniform.

Similar results were obtained for the grooved specimen; see Fig. 8.
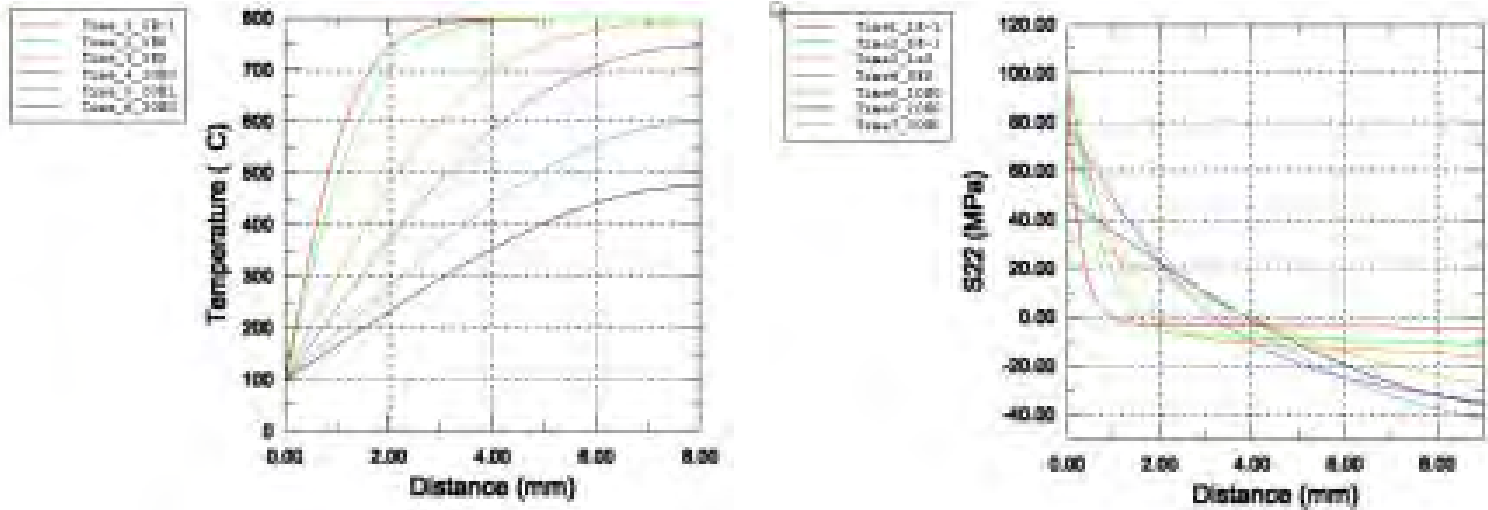

a). Through-thickness temperature distribution in cylindrical specimen without grooves

b). Through-thickness thermal hoop stress distribution in cylindrical specimen without grooves

Fig. 7. Transient temperature and thermal stress distributions in a cylinder without grooves
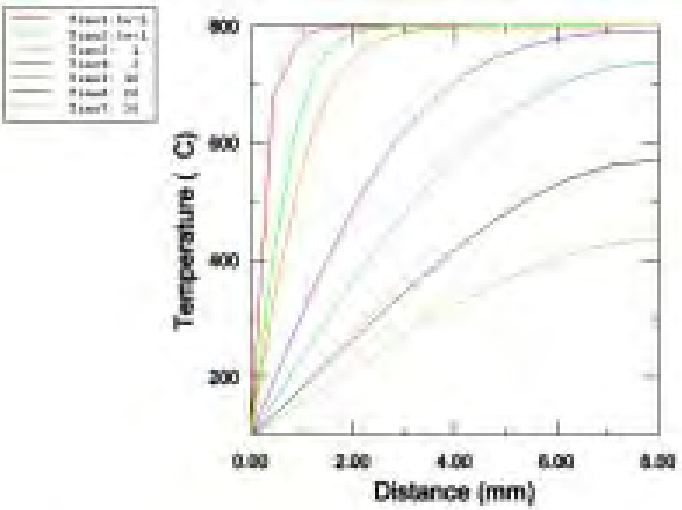

a). Through-thickness temperature distribution in cylindrical specimen with grooves
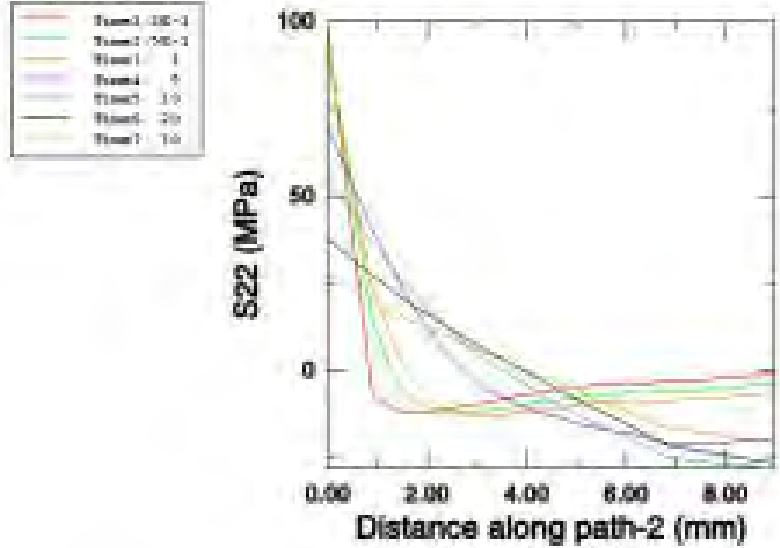

b). Through-thickness thermal hoop stress distribution in cylindrical specimen with grooves

Fig. 8. Transient temperature and thermal stress distributions in a cylinder with grooves

\subsection{Dynamic analysis following primary cracking}

The exact condition for, and hence the precise moment of, the initiation of the primary crack was not certain. Therefore, different initiation times were assumed for the primary crack. Thermal stress fields extracted from the thermal transient analysis at different times during the thermal transient were used as initial conditions for the dynamic analysis. By comparing the resulting dynamic responses, focusing in particular on the position of peak stress amplification, with the observed secondary crack position, the approximate initiation time for primary cracking was inferred.

Figure 9 shows the hoop stress time histories extracted from several positions, relative to the primary crack, from the cylinder without grooves. It can be seen from Fig. 9a that, if primary cracking occurs at $t=0.5 \mathrm{~s}$ after quenching, the resulting peak tensile stress amplification is achieved on the outer surface at a location $90^{\circ}$ from the primary crack (compressive stresses are ignored as brittle materials are much stronger in compression than in tension). This shifts to the inner surface at a location $180^{\circ}$ from the primary crack, i.e. the secondary crack 
position observed in experiment, if the primary crack is assumed to occur at $2 \mathrm{~s}$ or more into the quenching process (Figs. 9b-d). Figure 10 shows the positions on the cylinder corresponding to the two main stress peaks in the time histories. The results for the peak stress amplification are further summarized in Table 3.
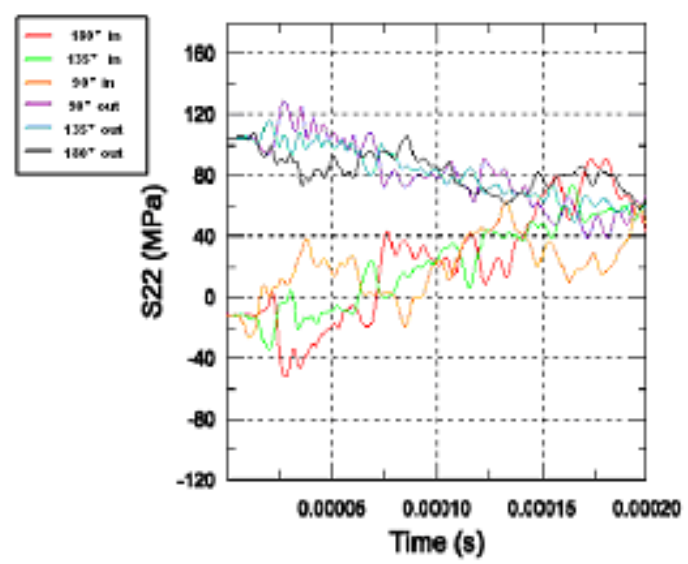

a). $t=0.5 \mathrm{~s}$
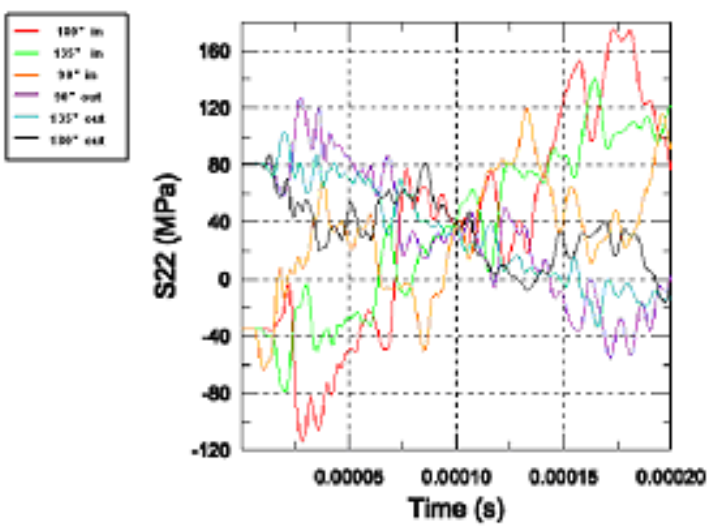

c). $t=5 s$
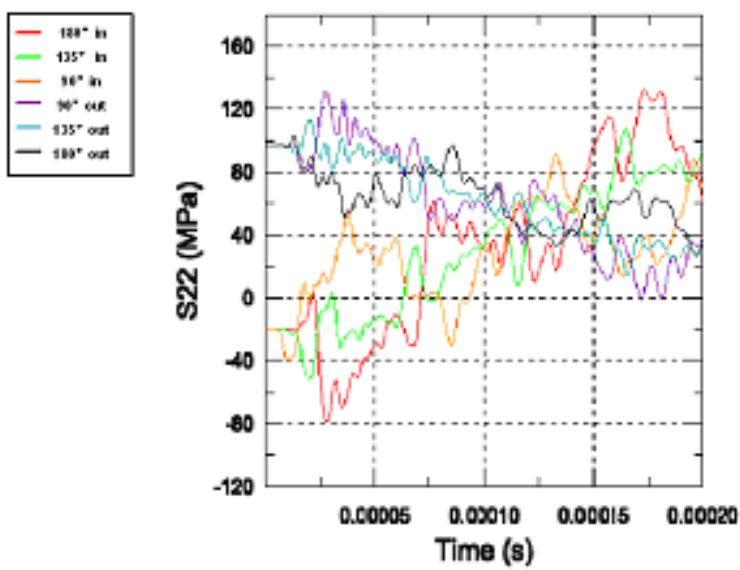

b). $t=2 s$
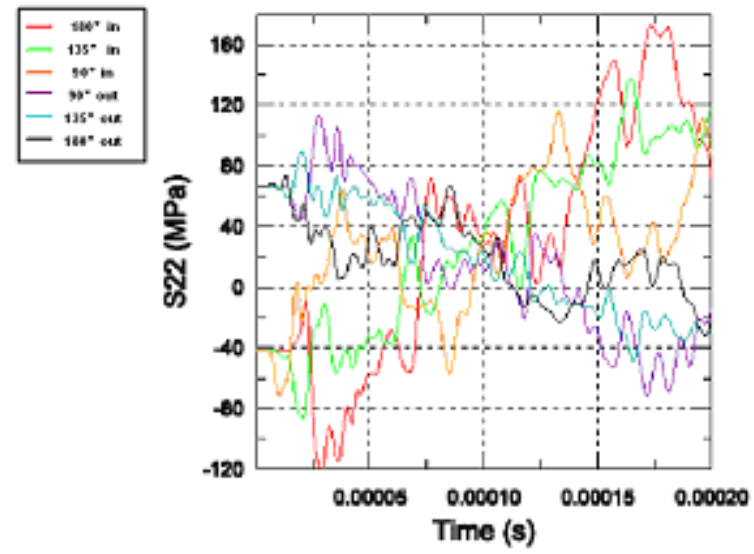

d). $t=10 \mathrm{~s}$

Fig. 9. Dynamic responses following primary cracking ( $t$ is the assumed initiation time for primary cracking to occur) 


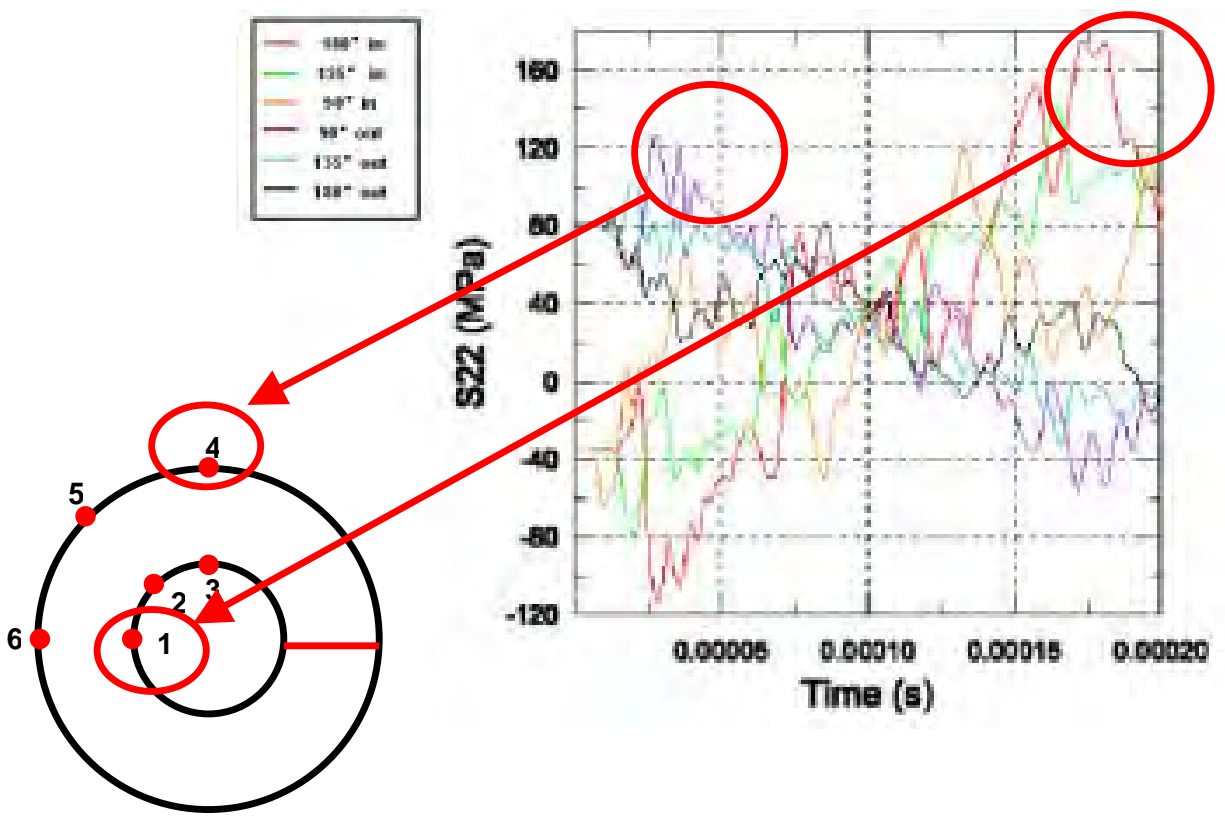

Fig. 10. Positions of stress peaks on cylinder

\begin{tabular}{|c|c|c|}
\hline $\begin{array}{c}\text { Time of Assumed } \\
\text { Primary Cracking (s) }\end{array}$ & $\begin{array}{c}\text { Position of Peak Stress } \\
\text { Amplification }\end{array}$ & $\begin{array}{c}\text { Magnitude of Peak Stress } \\
\text { Amplification }\end{array}$ \\
\hline \hline 0.5 & ${90^{\circ}}^{\circ}$ & 1.24 \\
\hline 2 & ${90^{\circ}, 180^{\circ}}^{\circ}$ & 1.38 \\
\hline 5 & $180^{\circ}$ & 2.1 \\
\hline 10 & $180^{\circ}$ & 2.5 \\
\hline 20 & $180^{\circ}$ & 2.88 \\
\hline
\end{tabular}

Table 3. Position and magnitude of peak stress amplification assuming different initiation times for primary cracking

Similar results were again obtained for the cylinder with grooves. However, in this case, stress sampling must be avoided at the groove tip position where a stress singularity exists.

\section{Discussion}

It is possible that the observed double cracks occurred simultaneously. However, since they always seemed to appear diametrically opposite to each other, it is more likely that there was a systematic mechanism linking the two, albeit a mechanism with a very short time scale between the primary and secondary cracking. As demonstrated by the above analysis, stress amplification from dynamic effects generated by the primary crack, which had a time scale of $0.2 \mathrm{~ms}$, would meet such a requirement. Incidentally, this also justifies the decoupling of the dynamic analysis from the thermal one, which had a much longer time scale of about 30 to $50 \mathrm{~s}$. Thus, the thermal transient would appear to be rather 'static' in relation to the dynamic process. 
It is almost certain that the primary crack would initiate from a $\mathrm{V}$-groove, if present, since the thermal stresses were highest on the outer surface and they would be further enhanced by the stress concentrating $\mathrm{V}$-groove. Some of the specimens had one of the cracks not running through the particular V-groove even though it was in the close vicinity. These were considered to be the secondary cracks and their morphology suggested that they had initiated from the inner surface.

The F.E. analysis indicated that, for secondary cracking to occur at $180^{\circ}$ from the primary crack, the latter must initiate at least $2 \mathrm{~s}$ after the start of quenching. Also, the secondary crack was predicted to initiate from the inside of the cylinder. Both of these predictions were in accord with experimental observations. It follows that the maximum stress failure criterion may not be strictly applicable to the onset of primary cracking in cylinders subjected to quenching, since the hoop stress on the outer surface was highest right at the beginning of quenching and yet fracture did not occur immediately. Alternative failure criteria need to be considered.

Figure 11 shows the change in the total strain energy of the cylinder during the thermal transient. It can be seen that, starting from zero, the total strain energy reaches its maximum value at about $4 \mathrm{~s}$ into quenching, i.e. the approximate time observed in the experiments when cracking took place and the time required by the numerical prediction for primary cracking to occur in order to produce diametrically opposite double cracks. Thus, it seems reasonable to conclude that primary cracking in cylindrical specimens subjected to quenching occurs when the total strain energy reaches a critical value. Since the maximum strain energy is proportional to the heating temperature, this also explains why the cylinders needed to be heated to a sufficiently high temperature before cracking could take place, even though stresses much higher than their static strength could be achieved with a lower heating temperature.

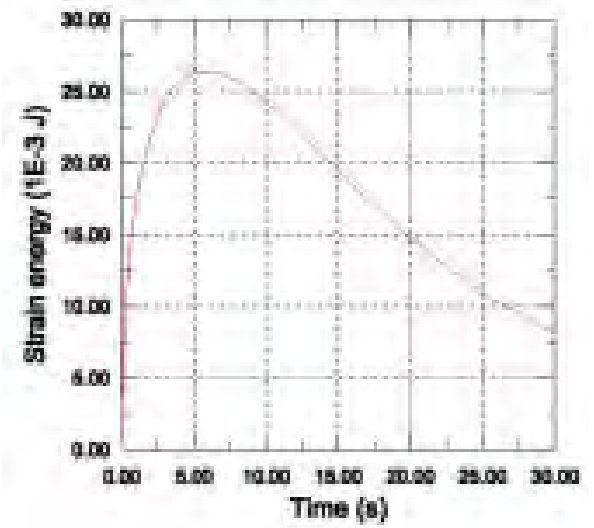

a). Total strain energy in ungrooved hollow cylindrical specimen

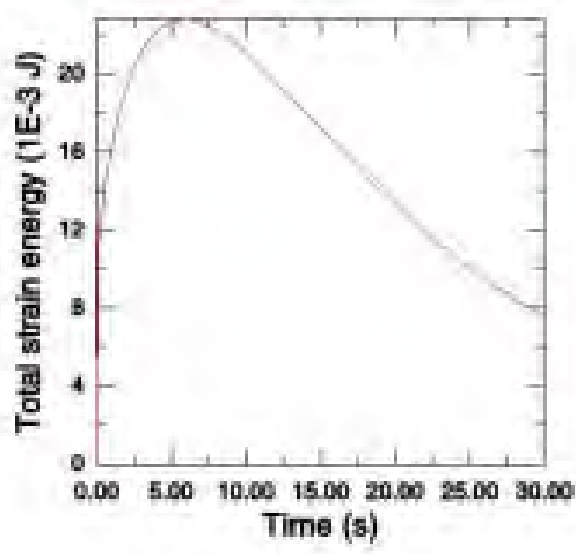

b). Total strain energy in grooved cylindrical specimen

\section{Fig. 11. Time history of total strain energy of cylinders during thermal transient}

Similarly, the maximum stress failure criterion does not seem to be applicable to the onset of secondary cracking either. From Fig. 9, it can be seen that dynamic stresses much higher than the static strength of the material had occurred earlier in the time history at positions other than the inner surface $180^{\circ}$ from the primary crack, and yet only one out of the twenty-four specimens tested did not fracture with diametrically opposite cracks.

There was, though, a relatively small stress peak on the outer surface, $180^{\circ}$ from the primary crack, which occurred right at the start of the time history; see Fig. 9. However, given that the secondary crack morphology indicated that it had initiated from the inner surface, this small stress peak was considered not to be responsible for secondary cracking.

Damping has previously been shown to have a negligible effect on the initial stress peaks during the dynamic response following primary cracking (Ref. 5). Considering the consistent double fracture behaviour observed in the experiments, its exclusion from the analysis was perhaps justified. However, it is possible that damping from 
the water may have prevented further cracking from taking place, such as the multiple cracks observed in the internal pressure tests (Refs. 3 and 4).

The work presented in this paper represents only a preliminary analysis of the quench test results. Additional work, both experimental and numerical, is required to further verify the theory proposed for the double cracking of cylindrical specimens subjected to thermal loading. Experimentally, the use of thermal loading in a dry environment which allows more data, such as cylinder temperature and strains, to be gathered would help to pinpoint the exact moment and position of both primary and secondary cracking. It is also important to test other brittle materials to see whether double cracking can be reproduced using them. The use of fracture mechanics analysis would shed more light on the onset of cracking and thus help to formulate a fracture criterion for brittle materials under transient and dynamic loadings.

\section{Conclusions}

- Hollow cylindrical specimens made of Pyrophyllite mainly fractured with two diametrically opposite cracks along the longitudinal axis when they were subjected to quenching.

- The lack of other fracture patterns indicates a systematic mechanism linking the two cracks.

- The primary crack seemed to occur at the stage when the total strain energy of the cylinder reached a critical value.

- Examination of the crack morphology indicated that the secondary crack was initiated at the inner surface of the cylinder.

- The occurrence of the secondary crack can be explained by stress amplification due to dynamic loads generated following primary crack.

\section{Acknowledgements}

The financial support of the UK Health and Safety Executive for this work is gratefully acknowledged. The views expressed in this paper are those of the authors and do not necessarily represent the views of the Health and Safety Commission/Executive.

\section{Reference}

1. Miklowitz J, Elastic waves created during tensile fracture - phenomenon of a second fracture, J Appl Mech 20 (1952), 122-130.

2. Shindler HJ and Kolsky H, Multiple fractures produced by the bending of brittle beams, J Mech Phys Solids 31 (1983), 427-437.

3. Sato $\mathrm{Y}$ and Hashimoto A, Failure of hollow cylinders of brittle materials under internal gas pressure, $\mathrm{J}$ Mater Sci Soc Jpn 20 (1983), 59-65 (in Japanese).

4. Sato $\mathrm{Y}$ and Hashimoto A, The fracture of hollow cylinders of brittle materials under dynamic internal gas pressure, Trans Jpn Soc Mech Eng A 52 (1986), 1290-1294 (in Japanese).

5. Kuroda M, Fok SL, Marsden BJ and Oyadiji SO, Analyses of the multiple cracking behaviour of brittle hollow cylinders under internal pressure, Int J Impact Eng, in press.

6. ABAQUS/Standard User's Manual, Version 6.1, Hibbit, Karlsson and Sorensen, Inc. 